\title{
Abatement costs of soil conservation in China's Loess Plateau: Balancing income with conservation in an agricultural system
}

\author{
Lingling Hou ${ }^{a}$, Dana L.K. Hoag ${ }^{b}$, , Catherine M.H. Keske ${ }^{c, 1}$ \\ a Center for Chinese Agricultural Policy, Institute of Geographic Sciences and Natural Resources Research, Chinese Academy of Sciences, \\ Jia 11 Datun Road, Chaoyang District, Beijing 100101, China \\ ${ }^{\mathrm{b}}$ Department of Agricultural and Resource Economics, Colorado State University, B330 Clark Bldg., Fort Collins, CO 80523-1172, USA

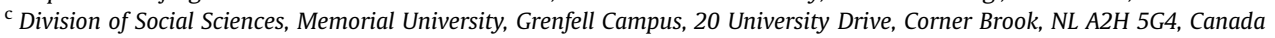

\section{A R T I C L E I N F O}

\section{Article history:}

Received 7 November 2013

Received in revised form

27 June 2014

Accepted 1 September 2014

Available online 17 October 2014

\section{Keywords:}

Abatement costs

Directional output distance function

Loess Plateau

Soil degradation

Cropping systems

\begin{abstract}
A B S T R A C T
This study proposes the use of marginal abatement cost curves to calculate environmental damages of agricultural systems in China's Loess Plateau. Total system costs and revenues, management characteristics and pollution attributes are imputed into a directional output distance function, which is then used to determine shadow prices and abatement cost curves for soil and nitrogen loss. Marginal abatement costs curves are an effective way to compare economic and conservation tradeoffs when field-specific data are scarce. The results show that sustainable agricultural practices can balance soil conservation and agricultural production; land need not be retired, as is current policy.
\end{abstract}

Published by Elsevier Ltd.

\section{Introduction}

Soil erosion is among the most serious environmental degradation issues in China. Ning (2013) estimates that increased sedimentation from soil erosion leads to reduced reservoir storage capacity and impaired shipping in waterways, which caused more than 28 billion RMB (about \$4.6 billion) of damage in 1997 . Increased salinization and soil run-off, as well as reduced crop yields and abandoned farmland, accounted for an additional 31.1 billion RMB ( $\$ 5.1$ billion) in damages (Ning, 2013). Wind erosion of soil resulted in 54 billion RMB more damages (Day, 2005). Environmental costs from sediment-related eutrophication of Chinese aquatic systems (Lee et al., 2013) would raise environmental damage estimates even more if calculated as they have been in the United States (Clark et al., 1985).

The precise location and impacts of environmental damage can be difficult to sort out, as are the incentives for individual farmers to reduce soil erosion. However, the central government has invested considerable resources since the mid-1990's to improve its

\footnotetext{
* Corresponding author. Tel.: +1 970491 5549; fax: +1970 4912067.

E-mail addresses: llhou.ccap@igsnrr.ac.cn (L. Hou), dana.hoag@colostate.edu (D.L.K. Hoag), ckeske@law.du.edu (C.M.H. Keske).

${ }^{1}$ Tel.: +1970 3727966 .
}

agricultural and environmental accounting (Wu, 2009). Agricultural land is typically owned by the Chinese central government, with long-term land leases and contracts administered by local villages. The long-term agricultural leases may be collectively reallocated for any number of reasons, including family size ( $\mathrm{Ho}$, 2001). Ambiguous property rights obfuscate individual and community incentives to reduce agricultural production on the land, especially with respect to the push to increase production to meet national food security policies (Brown, 1995; Ho, 2001). As is the case with the presenting study, incomplete information about land use tenure, field-level production, and environmental accounting necessitate the use of simulation to plan and manage conservation on agricultural land (Ho, 2001). However, as shown in the presenting study, simulation can play an important role in helping policy makers improve conservation management in the absence of detailed field data.

Soil erosion is particularly problematic in China's Loess Plateau, which is often cited as one of the country's most fragile and complex agricultural regions (Hou, 2012). The region has historically been noted for its agricultural production and rich soils, which drew human settlement along the Yellow River (Laflen et al., 2000). Soil loss in the Loess Plateau accounts for more than $90 \%$ of the total sediments entering the Yellow River (Chen et al., 2007). About 70\% of the total area is affected by soil erosion, and $40 \%$ of agricultural lands suffer annual losses of more than 50 ton/ha (Lu et al., 2003). 
Other estimates place annual soil erosion between 40 and 70 tons/ha (FAO/IAEA, 2013). By contrast, average annual soil erosion rates in the U.S. are approximately 17 tons/ha (Pimentel et al., 1995).

The urgent need for soil conservation policies in the Loess Plateau is widely recognized by ecologists, environmentalists and policy makers (e.g. Rozelle et al., 1997; Wang, 2004; Bindraban et al., 2012). Policy responses have been commensurately ardent. The extensive Grain for Green (GfG) program, for example, coarsely requires cropland retirement, virtually eliminating both erosion and crop income. However, abolishing agricultural production in a region may create other imbalances. This study proposes using a directional output distance function methodology to calculate nitrogen and soil loss from Loess Plateau agricultural systems. Calculating marginal abatement cost curves for these systems would enable policy makers to balance soil conservation with agricultural crop production, rather than eliminate crop production altogether. The presenting study posits that this methodology is the most appropriate approach for measuring soil and nitrogen loss of an entire agricultural system when field-level data are scarce.

To place this study in context, the Loess Plateau region epitomizes the confluence of challenges facing modern-day China. Environmental management involves balancing soil conservation with a culture engrained in agricultural production, while simultaneously considering national policy goals aimed to feed the growing population and increase household income. In their seminal book, Laflen et al. (2000) summarize the complexity of the study region: "Truly, the Loess Plateau is not only the most erodible place on earth, but also one of the most interesting." (p. xiv in Forward).

As shown in Fig. 1, China's Loess Plateau is located in northern China. It is also known as the Huangtu Plateau. The Plateau spans 5 provinces and stretches along the upper, middle bend of Huang He, or Yellow River. The region is deemed to be of cultural and agricultural importance (Rui et al., 2002). While the retirement of agricultural lands under the GfG program might at first seem dramatic, the challenge of managing the region's soils and agricultural systems should not be underestimated (Rui et al., 2002).
There is some evidence to suggest that environmental management can be improved by increasing farmer autonomy. Xu et al. (2010) posit that gains in household income, program efficiency, and welfare will occur if farmers are given greater autonomy about what fields, if any, to include in a program like GfG. Specifically, Lu et al. (2003) and Dogliotti et al. (2004) present solid evidence that conservation cropping in the Plateau can effectively reduce soil erosion while also maintaining agricultural production because agricultural systems, land types, and cropping techniques vary across the steeply sloping lands. Furthermore, a 2005 World Bank project reports that farmers' incomes rose dramatically and erosion was reduced when farmers were introduced to sustainable farming practices (World Bank, 2005). Thus, a sustainable approach for the region would balance agricultural production with field retirement, instead of replacing all crop production with grass or trees. However, farmers and policy makers need information and education about which practices can reduce erosion and maintain income and where these practices are best suited.

The economic literature is flush with examples about how to balance "undesirable" outputs such as soil erosion with "desirable" outputs like crop production (Coggins and Swinton, 1996; Liu and Sumaila, 2010; Stoorvogela et al., 2004). Both market and nonmarket values should be considered. Broadly speaking, there are two stakeholder positions that can be used to assess the nonmarket value of commodities or services. From the consumer side, the travel cost and contingent valuation methods reflect trade-offs or sacrifices that people are willing to make in order to consume higher levels of environmental quality (Champ et al., 2003; Loomis and Keske, 2009). The other approach is to look at the abatement cost of undesirable outputs (e.g. agricultural pollutants) from a producer perspective, in terms of reducing desirable outputs (e.g. crops) that are jointly produced with undesirable outputs, like soil erosion (Färe et al., 1993; Coggins and Swinton, 1996; Färe et al., 2005). While each method has advantages, abatement cost curves reflect the polluter pays principle and present lower costs in comparison to expensive surveying methods required for contingent valuation (Molinos-Senante et al., 2010).

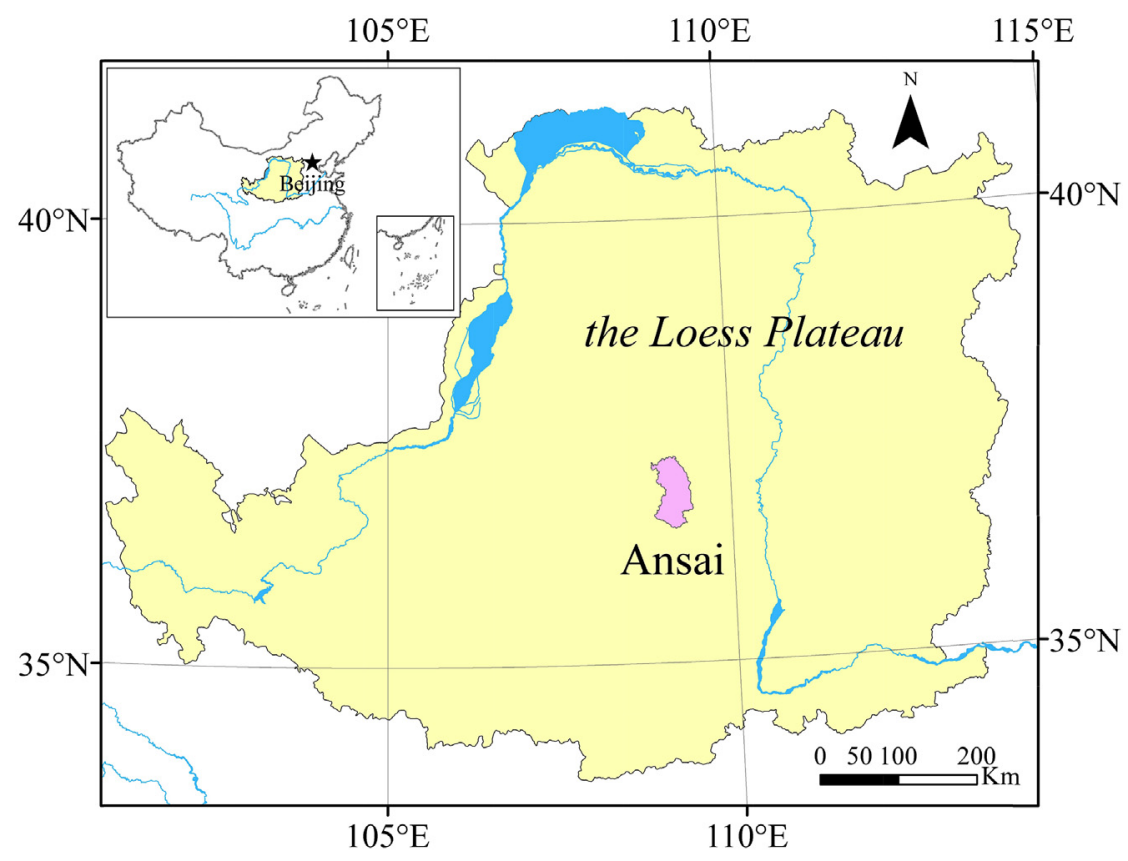

Fig. 1. Map of study area. The Loess Plateau is situated in the Ansai region of China. The Plateau spans five provinces. 
Since agricultural systems and fields in the Loess Plateau are heterogeneous (Lu et al., 2003), so are the field-level costs of avoided soil erosion damage within the system. A multitude of factors contribute to soil erosion propensity and soil erosion tolerance on individual fields or individual watersheds (Osmond et al., 2012), leading to heterogeneous on-farm costs at the field level. Off-farm costs are also likely to be highly variable. Hansen and Ribaudo (2008), for example, estimate that off-site costs of erosion in the United States vary considerably by field, with an average annual erosion cost between $\$ 1.70$ and $\$ 18.40$ per ton. While the costs of damages are not available for this study, avoidance costs are.

The presenting study incorporates a distance function approach to estimate the shadow prices for two undesirable contaminants, soil loss and nitrogen loss (Hou, 2012). Data from the region include inputs and outputs for 1720 cropping systems in the Plateau, first simulated and published by Lu et al. (2003). The cropping systems consist of different combinations of land units, crop rotations, production situations, terracing techniques, tillage methods, crop residue management techniques and mechanization levels. Additional details about these agricultural systems are presented in Table 1 and in Appendix B, and will be discussed later in the paper after the model is described. Costs, returns, erosion and nitrogen loss can be compared across systems, according to land type, rotation, tillage and other management variables. By controlling for production methods, the cost of preventing pollution (soil loss or nitrogen loss) can be measured as the opportunity cost of lost profit from crop production.

The distance function approach has been widely applied to estimate the abatement costs of pollution and the opportunity costs of environmental regulations. The distance function method was first developed by Färe et al. (1993), and further applied to shadow prices of pollution from pulp and paper industries (Hailu and Veeman, 2000), air pollution from electricity plants (Lee et al., 2002; Färe et al., 2005; Keske et al., 2012; Keske, 2011), and salmon aquaculture (Liu and Sumaila, 2010). Färe et al. (2006) later estimated shadow prices of polluting outputs and the associated pollution costs for U.S. agriculture from 1960 to 96 . In a related effort, Bond and Farzin (2007) estimated plot level shadow prices for agricultural pollutants in the United States.

The presenting study adds to the literature by estimating abatement cost curves for soil pollutants in the Loess Plateau to make the

Table 1

Summary of cropping systems identified and measured by Lu et al. (2003).

\begin{tabular}{|c|c|}
\hline Characteristics & Specifications \\
\hline Land units & $\begin{array}{l}\text { Includes } 5 \text { units classified by land slope: floodplains, } \\
\text { gently sloped land, moderately sloped land, steeply } \\
\text { sloped land, and very steeply sloped land. }\end{array}$ \\
\hline Crop rotation types ${ }^{\mathrm{a}}$ & $\begin{array}{l}\text { Includes } 2 \text { mono crops, } 8 \text { types of rotations without } \\
\text { alfalfa and } 7 \text { types of rotations with alfalfa. The } 2 \\
\text { mono crops are } C \text { and W; the } 8 \text { types of rotation } \\
\text { without alfalfa are PsWC, CMPa, CSC, FWPaM, } \\
\text { PsWCM, MSC, WPaMCF, MSMPa; and the } 7 \text { types of } \\
\text { rotation with alfalfa are A3CM, A3CPaM, A3MPaM, } \\
\text { A4MPaM, FA5MC, FWA4MC, A3MCPaCM. }\end{array}$ \\
\hline Production situations & $\begin{array}{l}\text { Includes } 3 \text { situations with different availability of } \\
\text { water and nutrients: sufficient water and nitrogen, } \\
\text { water-limited and nitrogen-limited }\end{array}$ \\
\hline Terracing & $\begin{array}{l}\text { Includes } 3 \text { terracing situations: no terracing, bench } \\
\text { terracing, spaced terracing }\end{array}$ \\
\hline Conservation Techniques & $\begin{array}{l}\text { Includes } 4 \text { practices: contouring \& mulching, } \\
\text { contouring \& non-mulching, furrow-ridging \& } \\
\text { mulching, furrow-ridging \& non-mulching. }\end{array}$ \\
\hline Mechanization levels & $\begin{array}{l}\text { Includes } 2 \text { levels: human and animal labor, semi- } \\
\text { mechanization }\end{array}$ \\
\hline
\end{tabular}

${ }^{\mathrm{a}} \mathrm{A \#}=$ alfalfa and years, $\mathrm{C}=$ corn, $\mathrm{M}=$ millet, $\mathrm{F}=$ flax, $\mathrm{Ps}=$ Summer Potato, $\mathrm{Pa}=$ Autumn Potato, $\mathrm{S}=$ soybean, $\mathrm{W}=$ winter wheat. case that agricultural production does not need to be abandoned in order to meet the region's environmental targets. It might be more balanced to retire the plots contributing the greatest amount of pollution, where the marginal cost to abate the pollution is highest. Soil degradation is a serious concern in the Loess Plateau; yet, despite multiple studies in the region, no published study has looked at pollution abatement costs compared to returns generated by crop production. Marginal abatement cost calculations provide a desirable alternative environmental management solution to China's Grain for Green program, for example, because land need not systemically be removed from agriculture in order to reduce nitrogen and soil loss. The presenting study also provides a unique contribution to the literature because it demonstrates that it is possible to derive marginal abatement costs from heterogeneous agricultural systems using a directional output distance function. Methodologically speaking, this could be the best approach to measuring the environmental damage from agricultural systems that are being managed under a large national or regional policy where field-level data are scarce, as is the case of China's Loess Plateau.

The paper is organized, as follows. The directional output distance function methodology, the derivation of shadow prices, and the distance function estimation are summarized in Section 2. The cropping system simulation data for the Loess Plateau, originally created from the Environmental Policy Integrated Climate (EPIC) model, is presented in Section 3. Empirical results are reported in Section 4. Discussion and conclusions are provided in Section 5.

\section{Estimating abatement costs with a distance function model}

A distance function approach can be used to measure tradeoffs between desirable outputs (profit) and undesirable outputs (pollution) for any given level of input. Calculating these tradeoffs is not necessary when the conservation practice intended to decrease pollution simultaneously increases profit. Conservation tillage, for example, is profitable on some soils and presents no sacrifice for a producer, so all else equal; a rational producer would adopt the practice. However, conservation tillage is not widely adopted on a voluntary basis when the practice is not profitable. The distance function approach is ideally suited to identify tradeoffs in these situations.

Four steps are required to calculate an output distance function. ${ }^{2}$ First, production possibility sets are created. A production possibility set underlies all feasible input-output combinations for a given level of input; and a directional distance function corresponds precisely to one production possibility set. Input " $x$ ", in this case, is a fixed resource; so total cost of the agricultural system is fixed for each production possibility set. The desirable output is profit. The undesirable output is pollution. The technologies for different cropping systems that produce desirable and undesirable outputs jointly are represented by a production possibility set as follows:

$P(x)=\{(y, b): x$ can produce $(y, b)\}$,

where $x=\left(x_{1}, \ldots, x_{N}\right) \in \Re_{+}^{N}$ is a vector of $N$ inputs, $y=\left(y_{1}, \ldots, y_{M}\right) \in \Re_{+}^{M}$ is a vector of $M$ desirable outputs and $b=\left(b_{1}, \ldots, b_{J}\right) \in \Re_{+}^{J^{+}}$is a vector of $J$ undesirable outputs.

The second step is to link the production possibility set to distance functions. Given the production possibility set $P(x)$, a directional output distance function for the $i$ th observation $\left(x_{i}, y_{i}, b_{i}\right)$ is defined as the simultaneous maximum reduction in undesirable

\footnotetext{
${ }^{2}$ For additional mathematical support and detailed discussion, please see Appendix C.
} 
outputs and expansion in desirable outputs along a direction $g=\left(g_{y}, g_{b}\right)$. Since each possibility set is unique for an input level $x$, there exists a unique set of tradeoffs for every level of $x$. Its mathematical form is:

$$
D_{i}\left(x_{i}, y_{i}, b_{i} ; g_{y}, g_{b}\right)=\max \left\{\varphi_{i}>0:\left(y_{i}+\phi_{i} g_{y}, b_{i}+\phi_{i} g_{b}\right) \in P\left(x_{i}\right)\right\},
$$

where $D_{i}$ is the distance function value for the $i$ th observation $\left(x_{i}, y_{i}, b_{i}\right)$ given the directional vector $\left(g_{y}, g_{b}\right)$, and $\varphi_{i}$ is the simultaneous change of desirable and undesirable outputs satisfying $\left(y_{i}+\varphi_{i} g_{y}, b_{i}+\varphi_{i} g_{b}\right) \in P\left(x_{i}\right)$.

The directional distance function is a measure of efficiency for the $i$ th cropping system, representing the "distance" of the produced output bundle from the technically efficient production frontier along the directional vector $\left(g_{y}, g_{b}\right)$. The production frontier is constructed by a set of cropping systems, whose distance function equals zero, i.e. $D_{i}\left(x_{i}, y_{i}, b_{i} ; g_{y}, g_{b}\right)=0$. This means that there is no possibility for these systems to reduce undesirable outputs and expand desirable outputs; therefore they are called efficient technologies. Shadow prices are based on efficient systems only and do not include changes that increase cropping profits and reduce pollution (e.g. the previously proposed hypothetical conservation tillage scenario).

The third step is to define shadow price. The shadow prices of undesirable outputs are derived from the first order condition for maximizing net revenue subject to a production technology; maximizing revenue is equivalent to maximizing profit when subject to a fixed and shared input level. The mathematical form of derivation is as follows. Let $\mathbf{p}_{\mathbf{y}}=\left(p_{y 1}, \ldots p_{y M}\right) \in \Re_{+}^{M}$ represent desirable output prices and let $\mathbf{p}_{\mathbf{b}}=\left(p_{b 1}, \ldots, p_{b J}\right) \in \Re_{-}^{J}$ represent the negative undesirable output prices. The revenue function, which considers the negative effect generated by the undesirable outputs, is defined as:

$R_{i}\left(\mathbf{x}_{\mathbf{i}}, \mathbf{p}_{\mathbf{y}}, \mathbf{p}_{\mathbf{b}}\right)=\max _{y, b}\left\{\mathbf{p}_{\mathbf{y}} \mathbf{y}_{\mathbf{i}}+\mathbf{p}_{\mathbf{b}} \mathbf{b}_{\mathbf{i}}:(\mathbf{y}, \mathbf{b}) \in P(\mathbf{x})\right\}$

or

$R_{i}\left(\mathbf{x}_{\mathbf{i}}, \mathbf{p}_{\mathbf{y}}, \mathbf{p}_{\mathbf{b}}\right)=\max _{y, b}\left\{\mathbf{p}_{\mathbf{y}} \mathbf{y}_{\mathbf{i}}+\mathbf{p}_{\mathbf{b}} \mathbf{b}_{\mathbf{i}}: \mathbf{D}_{\mathbf{i}}\left(\mathbf{x}_{\mathbf{i}}, \mathbf{y}_{\mathbf{i}}, \mathbf{b}_{\mathbf{i}} ; \mathbf{g}_{\mathbf{y}}, \mathbf{g}_{\mathbf{b}}\right) \geq 0\right\}$.

Eq. (4) finds the most efficient system for any given resource level, $x$, where the sum of the revenue from the desirable output, $p_{y} y_{i}$, less the lost revenue from the undesirable output, $p_{b} b_{i}$, is maximized. Profit is maximized at this point, since $x$ is given and fixed. $P_{b}$ is not observable, but can be derived as shown by the steps below. Eq. (4) can be rewritten as:

$D_{i}\left(\mathbf{x}_{\mathbf{i}}, \mathbf{y}_{\mathbf{i}}, \mathbf{b}_{\mathbf{i}} ; \mathbf{g}\right)=\min _{p}\left\{\frac{R_{i}\left(\mathbf{x}_{\mathbf{i}}, \mathbf{p}_{\mathbf{y}}, \mathbf{p}_{\mathbf{b}}\right)-\left(\mathbf{p}_{\mathbf{y}} \mathbf{y}_{\mathbf{i}}+\mathbf{p}_{\mathbf{b}} \mathbf{b}_{\mathbf{i}}\right)}{\mathbf{p}_{\mathbf{y}} \mathbf{g}_{\mathbf{y}}+\mathbf{p}_{\mathbf{b}} \mathbf{g}_{\mathbf{b}}}\right\}$

Applying the envelope theorem to Eq. (5) yields:

$\frac{\partial D_{i}\left(\mathbf{x}_{\mathbf{i}}, \mathbf{y}_{\mathbf{i}}, \mathbf{b}_{\mathbf{i}} ; \mathbf{g}\right)}{\partial b_{j}}=\frac{-p_{b j}}{p_{y} g_{y}+p_{b} g_{b}} \geq 0$

$\frac{\partial D_{i}\left(\mathbf{x}_{\mathbf{i}}, \mathbf{y}_{\mathbf{i}}, \mathbf{b}_{\mathbf{i}} ; \mathbf{g}\right)}{\partial y_{m}}=\frac{-p_{y m}}{p_{b} g_{y}+p_{b} g_{b}} \leq 0$

Thus, given the $m$ th desirable output price, say $p_{y m}$, the shadow price of the $j$ th undesirable output can be recovered by taking the ratio of Eqs. (6) and (7): $\frac{p_{b j}}{p_{y m}}=\frac{\partial D_{i}\left(\mathbf{x}_{\mathbf{i}}, \mathbf{y}_{\mathbf{i}}, \mathbf{b}_{\mathbf{i}} ; \mathbf{g}\right) / \partial b_{j}}{\partial D_{i}\left(\mathbf{x}_{\mathbf{i}}, \mathbf{y}_{\mathbf{i}}, \mathbf{b}_{\mathbf{i}} ; \mathbf{g}\right) / \partial y_{m}}$

or

$p_{b j}=p_{y m}\left(\frac{\partial D_{i}\left(\mathbf{x}_{\mathbf{i}}, \mathbf{y}_{\mathbf{i}}, \mathbf{b}_{\mathbf{i}} ; \mathbf{g}\right) / \partial b_{j}}{\partial D_{i}\left(\mathbf{x}_{\mathbf{i}}, \mathbf{y}_{\mathbf{i}}, \mathbf{b}_{\mathbf{i}} ; \mathbf{g}\right) / \partial y_{m}}\right)$.

The previous equations depict the derivation of the shadow prices for the undesirable outputs. Eq. (8) implies that revenue is maximized where the marginal rate of transformation between an undesirable output and a desirable output equals the price ratio of the two. This point gives the most efficient tradeoff of profit for pollution given the prices of crops and the pollutant. Shadow price cannot be observed directly, but can be derived as shown in Eq. (9) by multiplying Eq. (8) by $P_{y m}$. The negative shadow prices of undesirable outputs are interpreted as marginal opportunity costs in terms of foregone desirable outputs (Färe et al., 2006). Marginal opportunity costs then represent marginal abatement costs.

The last step is parameterizing the distance function, since the derivatives of the distance function are utilized in Eq. (9). A linear programming technique is employed to calibrate the unknown parameters in the distance function following Färe et al. (2006). A detailed description of estimation technique is shown in Appendix C. A regular regression technique is not appropriate in this situation because the values of the distance function would not be known until the regression is estimated.

\section{Data}

Ansai County is located in the hilly gullies region of Loess Plateau, with a geographic location between $36^{\circ} 30^{\prime} 45^{\prime \prime}$ $\mathrm{N}-37^{\circ} 19^{\prime} 31^{\prime \prime} \mathrm{N}$ and $108^{\circ} 51^{\prime} 44^{\prime \prime} \mathrm{E}-109^{\circ} 26^{\prime} 18^{\prime \prime} \mathrm{E}$ (Fig. 1 ). It has a total area of $2950.2 \mathrm{~km}^{2}$, with about $95 \%$ covered by hilly loess and a small area of floodplain of Yanhe River. The elevation ranges from $997 \mathrm{~m}$ to $1731 \mathrm{~m}$, with a relative difference of $100-200 \mathrm{~m}$. As previously stated, the soil loss in Ansai County is among the most severe in China, and the terrain epitomizes northwest China's ecological fragility.

The region has a semi-arid climate with annual mean temperature of $8.6^{\circ} \mathrm{C}$ and annual mean precipitation of $\sim 500 \mathrm{~mm}$. Most of the precipitation falls between June and September. The soils are homogeneous, mostly formed on the deep and loose loess deposit, and are comprised of $60-75 \%$ silt, less than $15 \%$ clay, and less than $30 \%$ sand.

The agricultural sector is declining in Ansai County. The arable land decreased from $0.20 \mathrm{hm}^{2}$ per capita in 1998 to $0.15 \mathrm{hm}^{2}$ per capita in 2007. Although annual income per capita increased from 1504 RMB in 1998-3295 RMB in 2007, agricultural GDP accounted for $90 \%$ of the whole economy in 1989 , and only $21 \%$ in 2005 . The major grain crops in Ansai include maize, millet, potatoes, soybean and winter wheat. Seed flax and alfalfa are planted as oil crop and forage crop, respectively.

The cropping systems used in this study are presented in Table 1. The data reflect more than 2000 unique cropping systems in Ansai County of the Loess Plateau, each with different combinations of 5 land units, 17 crop rotations, 3 production situations, 3 terracing techniques, 2 tillage techniques, 2 crop residue management techniques and 2 mechanization levels. Each system represents a data point with a unique combination of land characteristics, crops and management that result in a unique cost, return, soil loss, and nitrogen loss. Readers interested in more detailed information about the data can find it in Appendix B or Hou, 2012.

The corresponding outputs of interest for the presenting study (yield, soil erosion and nitrogen loss) were simulated for each 
system using the Environmental Policy Integrated Climate (EPIC) model and validated with the experimental data as described by Lu et al. (2003). This simulation was conducted on the 2006 different cropping-system variations based upon Lu's original work (2000) and a subsequent publication that uses approximately 500 of these cropping systems (Lu et al., 2003). EPIC is a comprehensive simulation model designed to predict the effects of management decisions on soil, water, nutrient and pesticide movements and their combined impact on soil loss, water quality and crop yield (Gassman et al., 2005). Impacts consist of weather, surface runoff, water and wind erosion, nitrogen loss (leaching), pesticide fate and transport, crop growth and yield, crop rotations, tillage, plant environment control (drainage, irrigation, fertilization, furrow diking, liming), economic accounting, and waste management. Lu et al. (2003) developed the comprehensive dataset on soil, weather, crop management, fertilizer and other parameters to meet the basic requirements to run the model. Hundreds of equations are applied in EPIC to simulate processes such as crop growth and soil erosion.

In order to calculate total costs for each agricultural system, as required for the shadow pricing model, the production set includes seeds, nutrients, biocides, irrigation if applicable, farm equipment, labor, animal traction and tractors as inputs, crop yield and two agricultural contaminants as outputs. Because eight inputs are used and eight crops are produced in some cropping systems, indices are used for each cropping system. Total input use for a system, $x$, reflects the total costs in an agricultural system. Likewise, the output from a system with multiple crops is represented by total revenue.

This output distance function adaptation has been used in previously published applications that computed shadow prices from distance functions (Bond and Farzin, 2007). Shadow prices are measured as the opportunity cost of lost profit per unit of pollution prevention. This is feasible since total cost is controlled as a constant through the production possibility sets used as inputs for the distance functions. The prices are not updated to the current year in order to avoid any distortions caused by differential inflation rates, and in order to make the presenting study results consistent with prices used in Lu et al. (2003).

As previously mentioned, this study focuses on situations where tradeoffs between pollution and income are unavoidable. A condition of null-jointness between desirable outputs and undesirable outputs is required for distance functions, and implies that no crop can be produced without nitrogen loss or soil loss. These systems represent cases where conservation is profitable. Therefore, 286 cropping systems with zero soil loss are dropped, resulting in a total of 1720 observations.

Descriptive statistics for the inputs and outputs used in estimating the distance function are given in Table 2 . The means of total cost and total revenue are $3059 \mathrm{RMB} / \mathrm{ha}$ (485.6 US \$/ha) and 5240 $\mathrm{RMB} /$ ha (831.7 US \$/ha), respectively, for the 1720 cropping systems. The means of nitrogen loss and soil loss are $15.6 \mathrm{~kg} / \mathrm{ha}$ and $3,629 \mathrm{~kg} / \mathrm{ha}$, respectively. Not surprisingly, there is a wide range in both soil loss and nitrogen loss, with the minimum and maximum levels of $0.01 \mathrm{~kg} / \mathrm{ha}$ and $57.6 \mathrm{~kg} / \mathrm{ha}$ for nitrogen loss and $0.5 \mathrm{~kg} / \mathrm{ha}$ through $69,838 \mathrm{~kg} / \mathrm{ha}$ soil loss, respectively. This broad range illustrates that there is a wide range of environmental pollution within the heterogeneous agricultural system.

\section{Empirical results: shadow price and marginal abatement cost calculations}

In order to ensure that the estimation of the parameters remains within a realistic scale, each output and input is normalized by their respective mean values. The parameters in the quadratic functional that form of the distance function are estimated by the linear
Table 2

Descriptive statistics of the variables used in the distance function. ${ }^{\mathrm{a}}$

\begin{tabular}{lcccl}
\hline Variable & Mean & $\begin{array}{c}\text { Standard } \\
\text { Deviation }\end{array}$ & Minimum & Maximum \\
\hline Total cost (RMB/ha) & 3,059 & 591.1 & 1,426 & 4,910 \\
Total revenue (RMB/ha) & 5,240 & $1,536.5$ & 1,446 & 12,594 \\
Nitrogen loss (kg/ha) & 15.6 & 9.4 & 0.01 & 57.6 \\
Soil loss (kg/ha) & 3,629 & 7,961 & 0.5 & 69,838 \\
\hline
\end{tabular}

a 1 US dollar $=6.3$ RMB at year 2012

b Input index in the distance function.

c Desirable output index in the distance function.

programming technique described in Appendix A. The distance function values for each cropping system can be calculated by plugging the estimated parameters into the distance function, together with data on total cost, total revenue, soil loss and nitrogen loss. Utilizing Eq. (9), the shadow prices of soil loss and nitrogen losses are estimated, separately.

Several interesting types of transitional data are computed in order to measure shadow prices, or the marginal abatement cost (MAC), in terms of foregone crop profit. Table 3, for example, presents the abatement cost to change from any crop system to another. Changing from a reference system in the vertical column reduces $(-)$ or increases $(+)$ abatement costs by the amount indicated. For example, the most costly system for abatement is flaxwheat-potato-millet (fwpm). Changing from fwpm to wheat increases abatement costs by $156.47 \mathrm{RMB} / \mathrm{h}$. Changing from an alfalfa-based system increases abatement costs nearly $500 \mathrm{RMB} / \mathrm{ha}$. From here, the opportunity cost of each management practice can be determined as elaborated upon in Table C4 in Appendix C. For example, profits with no terracing are $6438 \mathrm{RMB} / \mathrm{ha}$. At the current shadow price for a given system, profits fall to $6317 \mathrm{RMB} / \mathrm{ha}$ when the shadow price of erosion is considered. Using this same example in Table C4, profits for bench terracing are $7471 \mathrm{RMB} /$ ha without accounting for the cost of erosion, and fall to $6827 \mathrm{RMB} /$ ha when accounting for erosion costs. More details about this result and other examples can be found in Appendix C.

As shown in Fig. 2, the MAC for soil erosion and nitrogen loss is plotted for all 1720 cropping systems to produce ten plots (5 land types for soil and 5 for nitrogen). The horizontal axis indicates the amount of current erosion or soil loss, not the amount of erosion or nitrogen loss actually reduced. The vertical axis represents the marginal cost of abatement per unit per hectare for preventing erosion or nitrogen loss at the current rate of loss. For example, the MAC curve for soil loss on steep land is downward sloping, indicating that more steeply sloped lands require lower marginal abatement costs because there is less opportunity cost of crop production, and vice versa. MAC for land eroding less than $10 \mathrm{t} / \mathrm{ha}$ is between about 80 and $110 \mathrm{RMB} / \mathrm{t}$, while the MAC for land eroding over $40 \mathrm{t} /$ ha is only around $40 \mathrm{RMB} / \mathrm{t}$. MAC for nitrogen loss slopes in the opposite direction compared to soil erosion, demonstrating the unique nature of each pollutant. The MAC is least expensive on highly eroding land, with the least opportunity cost of crop production.

MAC curves can be further derived for any one of these plots by a regression of the marginal abatement costs for any pollutant level. For example, the MAC plot and regression curve for soil loss on the steeply sloped land is presented in Fig. 3.

\section{Discussion and conclusions}

In summary, this paper estimates the shadow prices for abatement costs of soil loss and nitrogen loss by using an output distance function approach for over 1700 cropping systems in the Loess Plateau of China. This study demonstrates that, through the use of a 


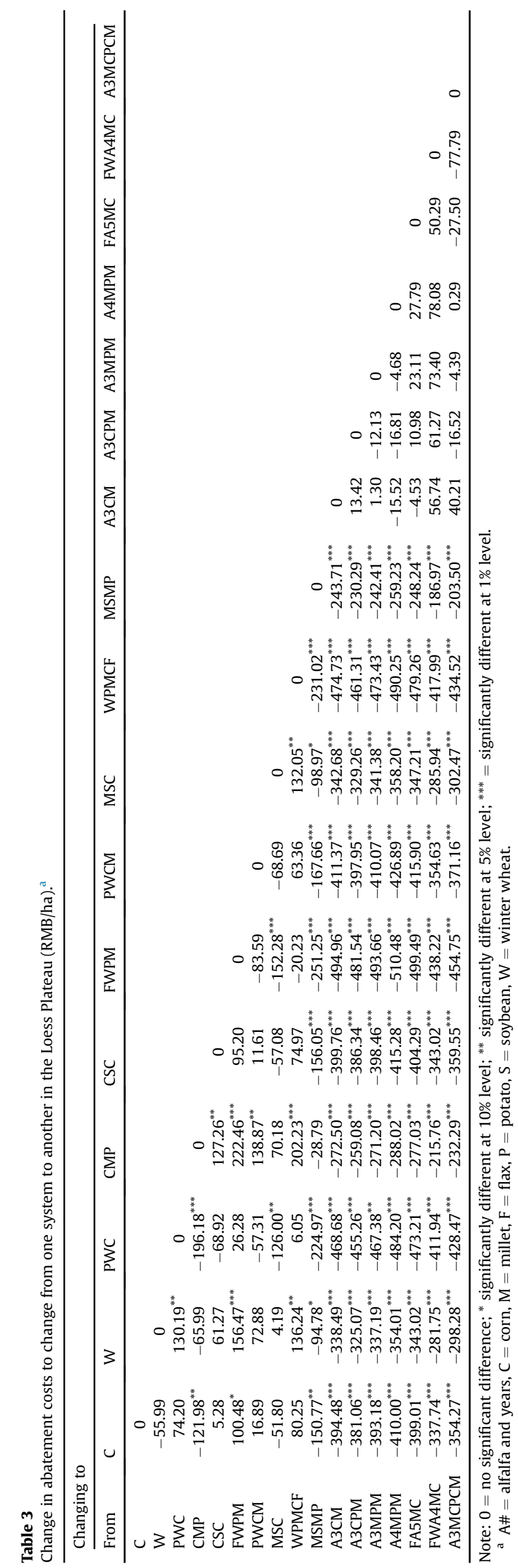

directional output distance function, MAC can be successfully derived from heterogeneous agricultural systems where field specific data are scarce. The marginal abatement cost of nitrogen loss averages $0.383 \mathrm{RMB} / \mathrm{kg}$, and ranges from 0.21 to $1.29 \mathrm{RMB} / \mathrm{kg}$. Soil loss has a mean marginal abatement cost of $0.102 \mathrm{RMB} / \mathrm{kg}$, and ranges from 0 to $0.162 \mathrm{RMB} / \mathrm{kg}$. Specific illustrations are derived and provided as examples. Interested readers may calculate other scenarios by using the transitional data available in Table 3 and in Appendix C, where other examples are provided.

The transitional data would also help determine which crops and cropping methods are most appropriate according to land type. Where soil erosion is concerned, more steeply sloping lands exhibit lower marginal abatement costs and it follows that the retirement of these lands could be prioritized under the current GfG program, or new programs. On the other hand, marginal abatement costs of reducing soil and nitrogen loss on flatter land is less predictable. Retiring these flatter lands under the GfG program may result in considerable foregone opportunity for agricultural production. In other words, the MAC model demonstrates that agricultural production need not be abandoned in the Loess Plateau, if lands for retirement are better targeted.

Farmer payments could also be distributed more effectively because the proposed methodology evaluates the MAC of specific production practices or land types. Since the GfG program offers farmers a financial incentive to retire cropland, it follows that farmer conservation payments should be commensurate with the opportunity cost of foregone profit. The net profit lost from pollution avoidance costs can be calculated by subtracting abatement costs calculated in Fig. 3 in the presenting study from ordinary profit calculated by Lu et al. (2003), available in the Appendix. For example, as shown in Fig. 4, there is no significant difference in profit between contouring and furrow ridging when undesirable, non-market pollution outputs are not included in calculations. If profit remains the same, farmers would arguably have no preference toward contouring or furrow ridging from the perspective of making profits, and thus should not receive payment. However, as shown by the second set of bars, contouring generates more profit than furrow ridging if the shadow prices of undesirable outputs are taken into account. This implies that policy makers could increase net welfare if government implements an incentive, like a subsidy, to direct farmers from furrow ridging to contouring practices where appropriate. The subsidy may be more effective on steeply sloped lands where the opportunity cost of foregone agricultural production is arguably higher than the flatlands.

An important consideration not addressed in this analysis is that foregone agricultural production could contribute to food security and nutrition issues. This may be a concern in rural areas that may be more difficult to reach due to their remote locations. Striking a balance between crop production and soil degradation targets is a goal that has been addressed by many national soil conservation policies that do not advocate intense land use changes (Hoag et al., 2012).

In the example presented in this paper, the MAC curves computed for soil erosion and nitrogen loss offer policy makers a method to develop policies that appropriately balance agricultural production with non-market goals. Without subsidies, and when loss of household income from agricultural production is considered, the sustainability of the worldwide conservation program GfG is questionable. Planting ecologically-friendly trees in place of intensive crop production benefits the environment, but fails to balance farmers' pursuit of income and the cultural importance of working lands (Cross et al., 2011). A balanced approach that considers these factors is possible, since agronomists provide solid scientific evidence that some cropping systems can balance both economic and environmental benefits (Laflen et al., 2000). 

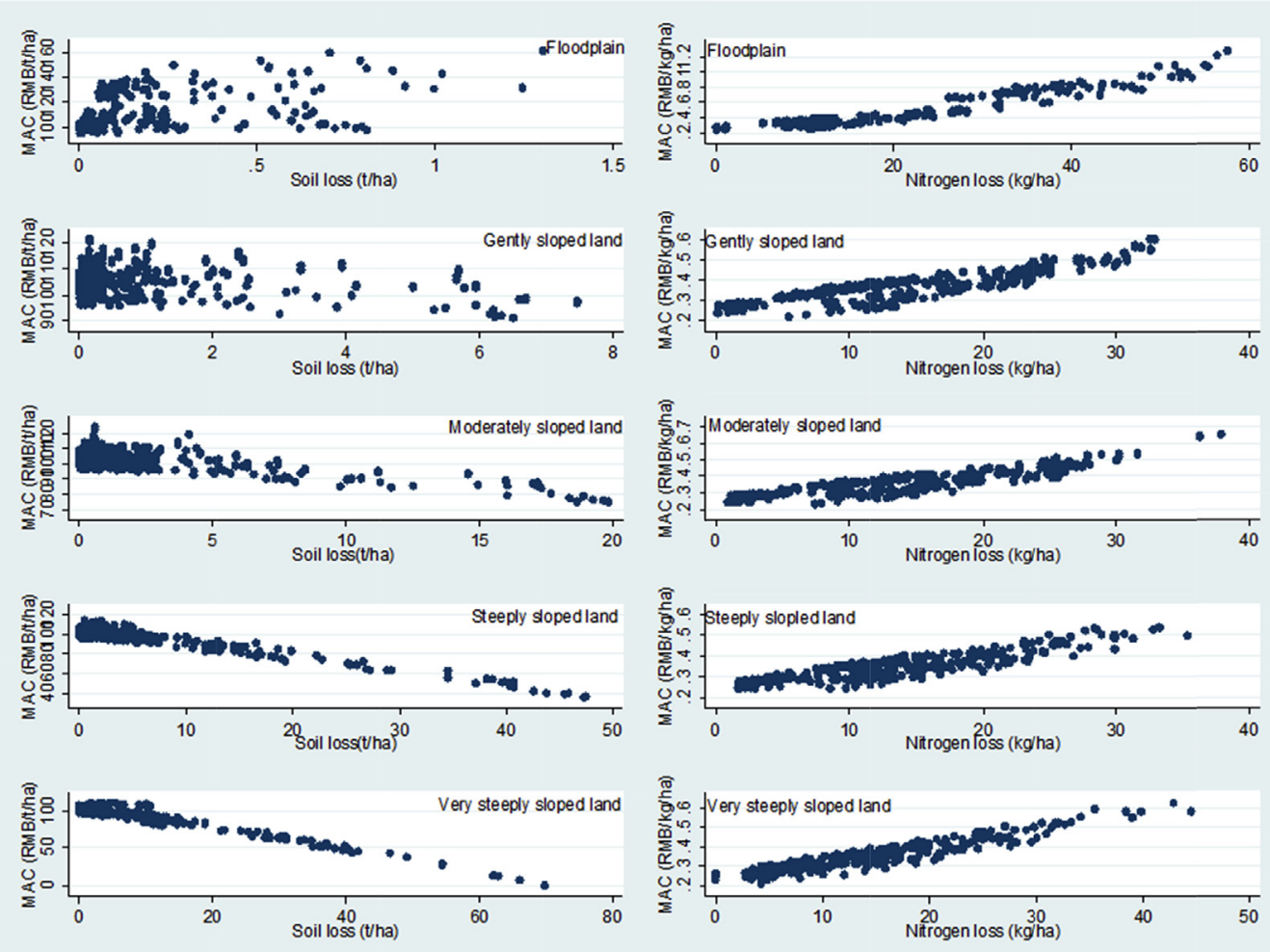

Fig. 2. Marginal abatement cost plots for soil loss and nitrogen loss for all five land types.

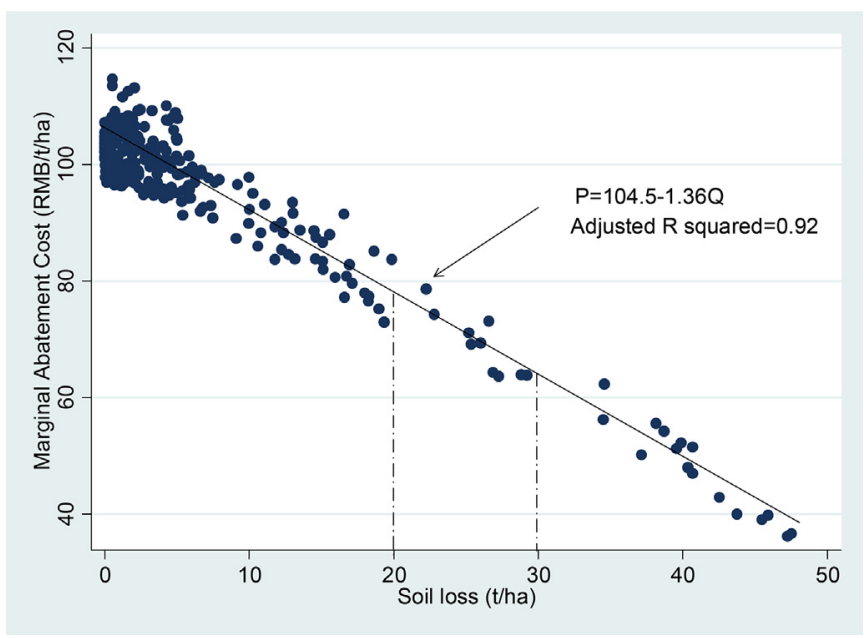

Fig. 3. Marginal abatement cost of soil loss for cropping systems on steeply sloped land. Note: $P$ represents the marginal abatement cost of soil loss (RMB/t); $Q$ represents the quantity of soil loss ( $t / h a)$.

The complexity and uniqueness of the Loess Plateau landscape and culture make it difficult to balance environmental conservation and economic development. China's rural land ownership policies are complicated (Ho, 2001), and community land allocation practices make it difficult to assess the individual incentives for agricultural producers to reduce soil erosion. However, the dilemmas facing the Loess Plateau are not dissimilar to situations experienced by developing nations across the globe. The proposed methodology can be used to help policy makers identify lands that may be retired at lower opportunity cost, effectively enabling farmers to switch to

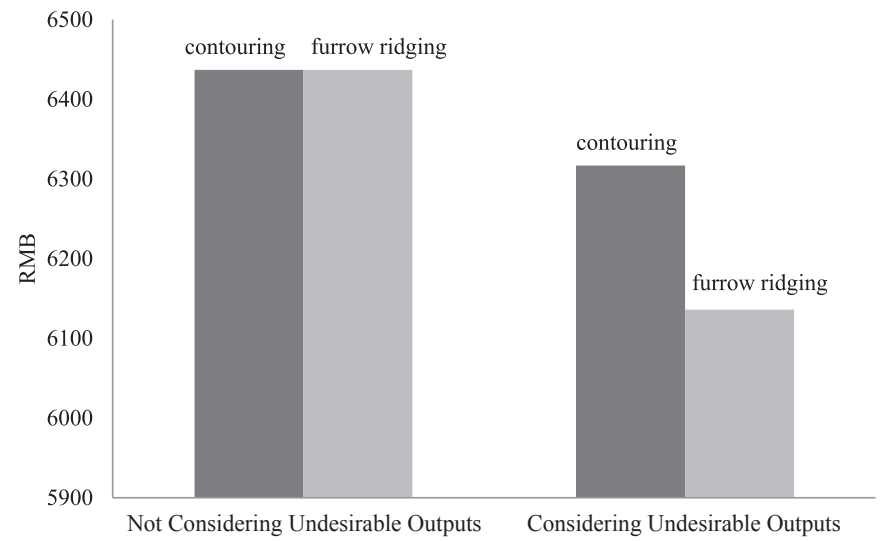

Fig. 4. Profit with and without considering the environment for contouring and furrow ridging practices.

more environmentally balanced cropping practices so that economic development and the environment can be balanced. By incorporating this methodology in the Loess Plateau, there is opportunity for China to lead by example.

\section{Acknowledgments}

The work is supported by National Natural Science Foundation of China (NSFC) (Project number 71303226) under the Youth Project "Sustainable Soil Management and its policies: A Case Study of Conservation Practices in the Northeast of China" (Project Number: 71303226), and the Key Program of the Chinese Academy of Sciences under a section "Evaluate the Impacts of Agricultural Non-point Pollution Abatement on Food Security and the Economy 
in Taihu Lake Watershed" (Project Number: KZZD-EW-10-04-2). Dr. Keske also acknowledges support from the National Science Foundation project, The Niwot Ridge Long-Term Ecological Research Program 2011-2016: Tipping Points in High-Elevation Ecosystems in Response to Changes in Climate and Atmospheric Deposition, Contract \#DEB-1027341.

\section{Appendix A. Supplementary data}

Supplementary data associated with this article can be found in the online version, at http://dx.doi.org/10.1016/j.jenvman.2014.09. 002 .

\section{References}

Bindraban, P., van der Velde, M., Ye, L., van den Berg, M., Materechera, S., Innocent Kiba, D., Tamene, L., Ragnarsdóttir, K.V., Jongschaap, R., Hoogmoed, M., Hoogmoed, W., van Beek, C., van Lynden, G., 2012. Assessing the impact of soil degradation on food production. Curr. Opin. Environ. Sustain. 4 (5), 478-488.

Bond, C., Farzin, Y.H., 2007. Estimating agricultural pollution abatement costs at the plot level using experimental data: a maximum entropy approach. J. Agric. Resour. Econ. 32 (2), 273-290.

Brown, L., 1995. Who Will Feed China? World Watch Institute, Washington, DC.

Champ, P.A., Boyle, K.B., Brown, T.C. (Eds.), 2003. A Primer on Nonmarket Valuation. Kluwer Academic Publishers, Dordrecht, The Netherlands.

Chen, L.-D., Wei, W., Fu, B., Lü, Y., 2007. Soil and water conservation on the Loess Plateau in China: review and perspective. Prog. Phys. Geogr. 31 (4), 389-403.

Clark, E.H., Haverkamp, J.A., Chapman, W., 1985. Eroding Soils: The Off-farm Impacts. The Conservation Foundation, Washington DC.

Coggins, J.S., Swinton, J.R., 1996. The price of pollution: a dual approach to valuing $\mathrm{SO}_{2}$ allowances. J. Environ. Econ. Manag. 30 (1), 58-72.

Cross, J.E., Keske, C.M.H., Lacy, M.G., Hoag, D.L.K., Bastian, C.T., 2011. Adoption of conservation easements among agricultural landowners in Colorado and Wyoming: the role of economic dependence and sense of place. Landsc. Urban Plan. 101 (1), 75-83.

Day, K.A. (Ed.), 2005. China's Environment and the Challenge of Sustainable Development. M.E. Sharpe, Armonk, New York, United States.

Dogliotti, S., Rossing, W.A.H., van Ittersum, M.K., 2004. Systematic design and evaluation of crop rotations enhancing soil conservation, soil fertility and farm income: a case study for vegetable farms in South Uruguay. Agric. Syst. 80 (3), $277-302$.

Färe, R., Grosskopf, S., Knox Lovell, C.A., Yaisawarng, S., 1993. Derivation of shadow prices for undesirable outputs: a distance function approach. Rev. Econ. Stat. 75 (2), 374-380.

Färe, R., Grosskopf, S., Noh, D.-W., Weber, W., 2005. Characteristics of a polluting technology: theory and practice. J. Econ. 126 (2), 469-492.

Färe, R., Grosskopf, S., Weber, W., 2006. Shadow prices and pollution costs in U.S. agriculture. Ecol. Econ. 56 (1), 89-103.

Food and Agriculture Organization of the United Nations, International Atomic Energy Agency (FAO/IAEA), 2013. Saving Millions of Tons of Agricultural Topsoil in China and Enhancing Livelihoods and Water Quality. Joint FAO/IAEA Division of Nuclear Techniques in Food and Agriculture. Available at: http://wwwnaweb.iaea.org/nafa/news/topsoil-china.html (accessed 24.06.14.).

Gassman, P.W., Williams, J.R., Benson, V.W., Izaurralde, R.C., Hauck, L.M., Jones, C.A., Atwood, J.D., Kiniry, J., Flowers, J.D., 2005. Historical Development and Applications of the EPIC and APEX Models. Center for Agricultural and Rural Development, Iowa State University. Report 05-WP397. Available at: http:// www.card.iastate.edu/publications/synopsis.aspx?id=763 (accessed 24.06.14.).

Hailu, A., Veeman, T.S., 2000. Environmentally sensitive productivity analysis of the Canadian pulp and paper industry, 1959-1994: an input distance function approach. J. Environ. Econ. Manag. 40 (3), 251-274.

Hansen, L., Ribaudo, M., 2008. Economic measures of soil conservation benefits: economic measures of soil conservation benefits. U.S. Department of
Agriculture, Economic Research Service Technical Bulletin Number 1922. Available at: http://www.ers.usda.gov/media/196118/tb1922.pdf (accessed 24.06.14.).

Ho, P., 2001. Who owns China's land? Policies, property rights and deliberate institutional ambiguity. China Q. 166, 387-414.

Hoag, D., Luloff, A. Osmond, D, 2012. Socio-economic analysis from the NIFA-CEAP projects. In: Osmond, D., Meals, D., Hoag, D., Arabi, M. (Eds.), How to Build Better Agricultural Conservation Programs to Protect Water Quality: The NIFACEAP Experience. Soil and Water Conservation Society, Ankeny, Iowa.

Hou, L., 2012. Soil Degradation in China: Implications for Agricultural Sustainability, Food Security and the Environment. Ph.D. Dissertation. Colorado State University, USA.

Keske, C.M.H., 2011. Costs of environmental and performance attributes of the Colorado electricity sector. Electr. J. 24 (9), 75-83.

Keske, C.M.H., Evans, S., Iverson, T., 2012. Total cost electricity pricing: a market solution for increasingly rigorous environmental standards. Electr. J. 25 (2), $7-15$.

Laflen, J.M., Tian, J., Huang, C.-H., 2000. Forward. In: Laflen, J.M., Tian, J., Huang, C.-H. (Eds.), Soil Erosion and Dryland Farming. CRC Press, Boca Raton, Florida.

Lee, J.-D., Park, J.-B., Kim, T.-Y., 2002. Estimation of the shadow prices of pollutants with production/environment inefficiency taken into account: a nonparametric directional distance function approach. J. Environ. Manag. 64 (4), 365-375.

Lee, S.S., Chang, S.X., Chang, Y.-Y., Ok, Y.S., 2013. Commercial versus synthesized polymers for soil erosion control and growth of Chinese cabbage. Springer Plus Environ. Sci. (2), 534

Liu, Y., Sumaila, U.R., 2010. Estimating pollution abatement costs of salmon aquaculture: a joint production approach. Land Econ. 86 (3), 569-584.

Loomis, J.B., Keske, C.M., 2009. Mountain substitutability and peak load pricing of high alpine peaks as a management tool to reduce environmental damage: a contingent valuation study. J. Environ. Manag. 90 (5), 1751-1760.

Lu, C.-H., 2000. Breaking the Spiral of Unsustainability: an Exploratory Land Use Study for Ansai, the Loess Plateau of China. Ph.D. dissertation. Wageningen University, The Netherlands.

Lu, C.-H., van Ittersum, M.K., Rabbinge, R., 2003. Quantitative assessment of resource-use efficient cropping systems: a case study for Ansai in the Loess Plateau of China. Eur. J. Agron. 19 (2), 311-326.

Molinos-Senante, M., Hernández-Sancho, F., Sala-Garrido, R., 2010, Economic feasibility study for wastewater treatment: a cost-benefit analysis. Sci. Total Environ. 408 (20), 4396-4402.

Ning, D., 2013. An assessment of the economic losses resulting from various forms of environmental degradation in China. Available at: http://www.homerdixon. com/projects/state/chinaeco/land.htm\#top (website accessed 24.06.14.).

Osmond, D., Meals, D., Hoag, D., Arabi, M. (Eds.), 2012. How to Build Better Agricultural Conservation Programs to Protect Water Quality: The NIFA-CEAP Experience. Soil and Water Conservation Society, Ankeny, Iowa:

Pimentel, D., Harvey, C., Resosudarmo, P., Sinclair, K., Kurz, D., McNair, M., Crist, S., Shpritz, L., Fitton, L., Saffouri, R., Blair, R., 1995. Environmental and economic costs of soil erosion and conservation benefits. Science 267 (5201), 1117.

Rozelle, S., Huang, J., Zhang, L., 1997. Poverty, population and environmental degradation in China. Food Policy 22 (3), 229-251.

Rui, L., Lui, G., Xie, Y., Oinke, Y., Liang, Y., 2002. Ecosystem rehabilitation on the loess plateau. In: McVicar, T.R., Rui, L., Walker, J., Fitzpatrick, R.W., Liu, C. (Eds.), Regional Water and Soil Assessment for Managing Sustainable Agriculture in China and Australia, ACIAR Monograph, vol. 84, pp. 358-365.

Stoorvogela, J.J., Antbel, J.M., Crissmanc, C.C., Bowend, W., 2004. The tradeoff analysis model: integrated bio-physical and economic modeling of agricultural production systems. Agric. Syst. 80 (1), 43-66.

World Bank, 2005. China - Second Loess Plateau Watershed Rehabilitation Project. World Bank, Washington, DC. http://documents.worldbank.org/curated/en/ 2005/12/6547341/china-second-loess-plateau-watershed-rehabilitationproject (website accessed 24.06.14.)

Wang, Y., 2004. Environmental degradation and environmental threats in China. Environ. Monit. Assess. 90 (1-3), 161-169.

Wu, F., 2009. Environmental politics in China: an issue area in review. J. Chin. Polit. Sci. $14,383-406$

Xu, J., Tao, R., Xu, Z., Bennett, M.T., 2010. China's sloping land conversion program: does expansion equal success? Land Econ. 86 (2), 219-244. 